\title{
(6) OPEN ACCESS \\ Age of first drinking and adult alcohol problems: systematic review of prospective cohort studies
}

\author{
Will Maimaris, Jim McCambridge
}

Faculty of Public Health \& Policy, London School of Hygiene \& Tropical Medicine, London, UK

\section{Correspondence to}

Dr Will Maimaris,

Faculty of Public Health \&

Policy, London School of

Hygiene \& Tropical Medicine,

Keppel Street, London WC1E

7HT, UK;

willmaimaris@yahoo.com

Received 20 September 2013 Revised 14 October 2013 Accepted 17 October 2013

Published Online First

18 November 2013

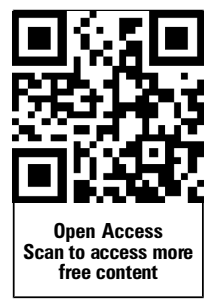

To cite: Maimaris W, McCambridge J. J Epidemiol Community Health 2014;68:268-274.

\section{ABSTRACT}

Background Alcohol policies around the world seek to delay the initiation of drinking. This is partly based on the influential idea that earlier initiation is likely to cause adult alcohol problems. This study synthesises robust evidence for this proposition.

Methods Systematic review of prospective cohort studies in which adolescent measurement of age of first drink in general population studies was separated by at least 3 years from adult alcohol outcomes. EMBASE, Medline, PsychINFO and Social Policy and Practice were searched for eligible studies, alongside standard nondatabase data collection activities. Data were extracted on included study methods and findings. Risk of bias and confounding was assessed for individual studies and a narrative synthesis of findings was performed.

Results The main finding was the meagre evidence base available. Only five studies were eligible for inclusion in this review. The existence of effects of age of first drink on adult drinking and related problems were supported, but not at all strongly, in some included studies, and not in others. Rigorous control for confounding markedly attenuates or eliminates any observed effects.

Conclusions There is no strong evidence that starting drinking earlier leads to adult alcohol problems and more research is needed to address this important question. Policy makers should, therefore, reconsider the justification for delaying initiation as a strategy to address levels of adult alcohol problems in the general population, while also addressing the serious acute harms produced by early drinking.

\section{INTRODUCTION}

Across the world a key aim of alcohol policy is to delay the age at which alcohol is first drunk, most obviously with legal minimum purchase ages. ${ }^{1} \mathrm{~A}$ key rationale for such policies is that an earlier age of first drinking (AFD) makes alcohol problems in adulthood more likely. For example the US Surgeon General's Call to Action on underage drinking states that; "approximately $40 \%$ of individuals who report drinking before age 15 also describe their behaviour and drinking at some point in their lives in ways consistent with a diagnosis for alcohol dependence. This is four times as many as among those who do not drink before age 21” (Ref. 1, p. 12). Similarly, the official UK guidance on alcohol consumption, which advises against any drinking before the age of 15 years, is supported by the statement that "early age of drinking onset is associated with an increased likelihood of developing alcohol abuse or dependence in adolescence and adulthood"(on page 52 ). ${ }^{2}$
Although, the US and UK guidance documents cite a number of, mostly cross-sectional, studies to support the proposed association between earlier AFD and harmful alcohol use in adulthood, a systematic appraisal of the nature and strength of the relationship between AFD and later harmful alcohol use has not previously been performed. ${ }^{3-6}$ An understanding of this relationship is important to determine the value of preventive interventions in reducing longer term alcohol harms. ${ }^{7}$ An underlying causal relationship between earlier AFD and adult alcohol problems could exist if there is neurobiological or other developmental impairment or if alcohol involvement is otherwise promoted, for example via peer networks. If any such causal relationship exists, widely delivered early interventions which delay AFD could make a significant contribution to reducing population levels of alcohol problems. If there is no causal relationship, however, delaying age of drinking initiation will not reduce levels of adult alcohol problems, though it may still confer other benefits in relation to adolescent harms. ${ }^{2}$ Within the research community there has been debate about whether there is an underlying causal relationship between earlier AFD and alcohol problems in adulthood, and opinion has been divided on this issue. ${ }^{689}$ Obvious importance to policy and practice makes imperative evaluation of the research evidence to ascertain the strength of any associations and the likelihood of causation. Here we conduct a systematic review of cohort studies to examine the association between AFD and adult alcohol problems and consider the evidence for a causal relationship.

\section{METHODS}

Cross-sectional studies are usually considered an inappropriate basis for causal inference, particularly so in relation to associations extending over time. Recall bias is an obvious threat. The longer the time interval between initiating drinking and reporting on it, the greater the scope for recall problems and telescoping forward, so as to report a later AFD. ${ }^{7}$ Adult problem drinkers may also have systematically different recall of their AFD, being more likely to report younger AFD, and/or different willingness to report it from those who do not have such problems. ${ }^{10}$ These problems also affect case-control studies. Cohort study designs which measure AFD prior to assessment of alcohol related harms provide a stronger basis for investigation of the strength of associations and consideration of possible causation. Particularly where measurement of AFD is soon after the event, they can potentially minimise recall bias and reduce the likelihood of differential reporting problems. A systematic review 
of cohort studies provides the strongest observational study design to evaluate evidence for causal inference. ${ }^{11}$ While experimental evidence would be preferable to observational evidence, there is sparse data on the effects of altering AFD due to the intractability of this intervention target. ${ }^{12}$

This report is guided by the Preferred Reporting Items for Systematic Reviews and Meta-Analyses (PRISMA) statement. ${ }^{13}$ The following selection criteria were applied: Studies which defined AFD as the age at which a participant had a first drink of more than a few sips of alcohol were included, while studies which assessed only age of first intoxication or the initiation of regular drinking were excluded, because these will widely occur at a later age. Only cohort studies comprising general population samples were included, with a requirement for at least 3 years follow-up between initial measurement of AFD in adolescence and the assessment of alcohol related outcomes. This interval, somewhat arbitrarily allows for the development of problems after initiation. Included studies were also required to measure alcohol related outcomes in adulthood, defined here as 18 years or over. Studies of special populations such as children of alcoholics were excluded. Relevant alcohol related outcomes were defined as: measures of consumption, including measures of the frequency and quantity of alcohol use; Diagnostic and Statistical Manual of Mental Disorders or International Classification of Diseases defined alcohol dependence or non-dependence alcohol problems ${ }^{14}{ }^{15}$; or other measures of harmful alcohol use, such as getting into fights while under the influence of alcohol. Studies were eligible for inclusion only if they reported the magnitude of an association between age of first drink and any of these alcohol related outcomes, for example, in the form of an OR or regression coefficient. Only peer reviewed studies were included. No language or date restrictions were applied.

A search of the following databases for eligible studies was performed from inception to the present on 10 January 2013: Medline, Embase, PsychInfo and Social Policy and Practice. The final search terms used in Psychinfo are presented in box 1. The database search was complemented by backward searching, involving screening the reference lists of included studies, and forward searching of subsequent citations of these papers.

Box 1 Database search strategy used in Ovid SP to search Psychinfo.

1. ("age at onset" or "age of onset" or " first drink" or "age at first use" or "age at initiation" or "age of initiation" or "early initiation").ab.

2. age of onset.sh.

3. 1 or 2

4. ("drinking" or "alcohol").ab.

5. (alcohol or drinking).sh.

6. 4 or 5

7. 3 and 6

8. ("alcohol-related problems" or "alcohol related problems" or "alcohol abuse" or "alcohol dependence" or "problem drinking" or "problem-drinking" or "hazardous drinking" or "hazardous-drinking" or "alcohol use" or "addiction" or "alcoholism").ab.

9. (alcohol abuse or alcohol dependence or problem drinking or hazardous drinking or addiction or alcoholism).sh.

10. 8 or 9

11. 10 and 7
Further relevant studies were identified by contacting 20 experts in this subject area of young people's drinking, and by screening the references of a recent, related review which also informed the design of the present study. ${ }^{16}$ Screening of abstracts was undertaken by the first author and both authors independently reviewed selected full texts for suitability of inclusion.

In addition to the data presented in table 1 , the following data were extracted from the included studies using a dedicated form: Type of AFD variable (binary, categorical or continuous), data collection method (self-completion questionnaire or face to face), details of statistical analyses performed, unadjusted results and findings from subgroup analyses.

A narrative analysis of the included studies was undertaken. Meta-analyses were not performed because they were judged inappropriate due to heterogeneity in the methods and outcomes of the included studies. Primary study methods were appraised to evaluate the potential for confounding and bias, with particular attention paid to selection, attrition, recall and reporting biases. With regards to confounding, the level of control for important background psychosocial and familial risk factors for alcohol problems including socioeconomic status, family history of alcohol problems, mental health issues or other early evidence of behavioural problems was assessed. ${ }^{8} 17$

\section{RESULTS}

Only five studies met eligibility criteria for this review, ${ }^{18-22}$ three of which were published within the past 3 years. ${ }^{20-22}$ The PRISMA flow chart summarising the data collection process is shown in figure 1. Reports from four separate cohorts, comprising three reports from two US cohorts, ${ }^{19-21}$ and two reports from two cohorts in Norway ${ }^{18} 22$ were included. Sample sizes ranged from $447^{19}$ to $1311 .^{22}$ The cohorts were either school ${ }^{18} 20-22$ or community based. ${ }^{19}$ Study design, methods and results are summarised in table 1 .

Pedersen and Skrondal ${ }^{18}$ examined the effects of AFD in a school-based cohort of 522 participants. They defined AFD as consumption of a half of bottle of beer, $100 \mathrm{~mL}$ of wine or $25 \mathrm{~mL}$ of spirits and chart initiation in annual waves of data collection, using the first reported age of drinking as a continuous variable for their analysis. Outcomes were measured in a single follow-up wave at age 18-21 years. After controlling for peer and parental influences in structural equation models they identify a large independent effect, strikingly estimating that a $10 \%$ delay in AFD would lead to a $35 \%$ reduction in subsequent alcohol consumption and also a large effect on alcohol problems. The authors acknowledged that more stringent control of confounding would weaken this association and that further studies were needed.

Warner and White ${ }^{19}$ selected those who provided data at all follow-up intervals from a larger cohort study and were assessed at the earliest age of 12 years, specifically to minimise recall bias in respect of AFD (median AFD was 10 years). The final sample size was 447. They separately enquired about AFD in family and other contexts and gathered data on various aspects of the experience of the first drinking episode. They defined early AFD as reported drinking prior to age 11 years. Data on AFD were collected at age 12 years, 15 years and 18 years, with additional follow-ups at age 25 years and age 30 years or 31 years. Early AFD in family (OR 2.39: 95\% CI 1.10 to 5.20) and other contexts (OR 5.75: 95\% CI 1.53 to 21.54 ) were associated with lifetime problem drinking by age 31 years in a model adjusting for various characteristics of the first drinking episode as well as gender, socioeconomic status and religion. However, neither AFD nor context of first drink was a statistically significant predictor of alcohol problems in a multivariate model adjusting 
Table 1 Study design, methods and key outcomes of included studies

\begin{tabular}{|c|c|c|c|c|c|c|c|}
\hline $\begin{array}{l}\text { Author and } \\
\text { year }\end{array}$ & $\begin{array}{l}\text { Cohort name, type } \\
\text { and location }\end{array}$ & $\begin{array}{l}\text { Final } \\
\text { sample } \\
\text { size }\end{array}$ & $\begin{array}{l}\text { Follow-up } \\
\text { rate }\end{array}$ & $\begin{array}{l}\text { Data collection points } \\
\text { for age of first drink } \\
\text { (AFD) and outcomes }\end{array}$ & $\begin{array}{l}\text { Alcohol-related outcomes } \\
\text { measured }\end{array}$ & Confounders included in multivariable analysis & $\begin{array}{l}\text { Key outcome data: } \\
\text { (OR, } 95 \% \text { Cls given in brackets where } \\
\text { available) } \\
\text { (AFD=age of first drink) }\end{array}$ \\
\hline $\begin{array}{l}\text { Pedersen and } \\
\text { Skrondal } 1998^{18}\end{array}$ & $\begin{array}{l}\text { School-based cohort } \\
\text { (Oslo, Norway) }\end{array}$ & 522 & $89 \%$ & $\begin{array}{l}\text { AFD data collected at: } \\
\text { T1 (12-15 years) } \\
\text { T2 (13-16 years) } \\
\text { T3 (14-17 years) } \\
\text { T4 (15-18 years) } \\
\text { T5 (18-21 years) } \\
\text { Outcomes measured at } \\
\text { T5 (18-21 years) }\end{array}$ & $\begin{array}{l}\text { Alcohol consumption } \\
\text { (past month) } \\
\text { Problem drinking (past year) as } \\
\text { measured by the Rutgers } \\
\text { Alcohol Problem Index (RAPI) }\end{array}$ & $\begin{array}{l}\text { Parental social norms. Parental smoking and alcohol use. } \\
\text { Parental alcohol problems. Friends' social norms. Friends' } \\
\text { alcohol and tobacco use. }\end{array}$ & $\begin{array}{l}\text { Alcohol debut age vs alcohol consumption } \\
\text { Structural equation coefficient }=-3.465 \\
\text { ( } p<0.0001) \text {. } \\
\text { Result roughly equates to a } 10 \% \text { delay in } \\
\text { alcohol debut resulting in a } 35 \% \text { reduction in } \\
\text { alcohol consumption } \\
\text { Alcohol debut age vs alcohol problem index } \\
\text { Structural equation coefficient }=-13.828 \\
(p<0.0001) \text {. }\end{array}$ \\
\hline $\begin{array}{l}\text { Warner and } \\
\text { White } 2003^{19}\end{array}$ & $\begin{array}{l}\text { Rutgers Health and } \\
\text { Human Development } \\
\text { Project. } \\
\text { Community based } \\
\text { cohort } \\
\text { (USA) }\end{array}$ & 447 & $83 \%$ & $\begin{array}{l}\text { AFD data collected at: } \\
\text { T1 (12 years) } \\
\text { T2 (15 years) } \\
\text { T3 ( } 18 \text { years) } \\
\text { Outcomes measured at } \\
\text { T1-T3 and: } \\
\text { T4 ( } 25 \text { years) } \\
\text { T5 ( } 30-31 \text { years) }\end{array}$ & $\begin{array}{l}\text { Lifetime incidence of problem } \\
\text { drinking (dependence or abuse) }\end{array}$ & $\begin{array}{l}\text { Gender. Religion. Parental status. Setting of first drink. } \\
\text { Pleasantness of first drink experience. Drunkenness at first } \\
\text { drink experience. Family history of alcoholism. Family and } \\
\text { friends' alcohol use. Strength of parental relationship. } \\
\text { Delinquency. Academic performance. Presence of psychiatric } \\
\text { symptoms. }\end{array}$ & $\begin{array}{l}\text { Lifetime problem drinking } \\
\text { AFD }<11 \text { years of age at a family gathering } \\
\text { vs AFD } 11 \text { years }+ \text { at a family gathering: } \\
O R=2.39(1.10-5.20) p<0.05 \\
\text { AFD }<11 \text { years outside a family gathering vs } \\
\text { AFD } 11 \text { years }+ \text { at a family gathering: } \\
\text { OR }=5.75 \text { ( } 1.53-21.54) p<0.01 \\
\text { Final multivariable model: Regression } \\
\text { coefficient for effect of AFD on problem } \\
\text { drinking }=-0.0631, p>0.05\end{array}$ \\
\hline $\begin{array}{l}\text { Rossow and } \\
\text { Kuntsche } 2013^{22}\end{array}$ & $\begin{array}{l}\text { The Young in } \\
\text { Norway } \\
\text { Longitudinal Study. } \\
\text { National } \\
\text { school-based cohort } \\
\text { study (Norway) }\end{array}$ & 1311 & $82.4 \%$ & $\begin{array}{l}\text { T1 (13-14 years) } \\
\text { Outcome data collected } \\
\text { at T2 ( } 26-27 \text { years) }\end{array}$ & $\begin{array}{l}\text { Heavy drinking (Drinking to } \\
\text { intoxication } 10 \text { or more times } \\
\text { in last } 12 \text { months) } \\
\text { Harmful alcohol use (AUDIT } \\
\text { score }=8 \text { or more) }\end{array}$ & $\begin{array}{l}\text { Gender } \\
\text { Conduct problems at T1. }\end{array}$ & $\begin{array}{l}\text { Model } 1 \text { : Controlling for gender only } \\
\text { OR for frequent intoxication: early AFD }(<13 / \\
14 \text { years) }=1.5(1.2-1.9) \text { vs late AFD. } p<0.01 \\
\text { OR for harmful alcohol use (AUDIT score } 8 \text { or } \\
\text { more): early AFD }=1.6 \text { (1.3-2.1) vs late AFD } \\
\mathrm{p}<0.01 \\
\text { Model } 2 \text { : Additional adjustment for conduct } \\
\text { problems: } \\
\text { OR for frequent intoxication: early AFD }(<13 / \\
14 \text { years)=1.2 ( } 0.9-1.6) \text { vs late AFD. } p>0.05 \\
\text { OR for harmful alcohol use (AUDIT score } 8 \text { or } \\
\text { more): early AFD }=1.2(0.9-1.6) \text { vs late AFD } \\
p>0.05\end{array}$ \\
\hline $\begin{array}{l}\text { Guttmannova } \\
\text { et al } 2011^{20}\end{array}$ & $\begin{array}{l}\text { Seattle Social } \\
\text { Development } \\
\text { Project. } \\
\text { School-based cohort } \\
\text { (Seattle, USA) }\end{array}$ & 808 & $92 \%$ & $\begin{array}{l}\text { AFD data collected at: } \\
\text { T1 (10-11 years) } \\
\text { T2 ( } 11-12 \text { years) } \\
\text { T3 (12-13 years) } \\
\text { T4 (13-14 years) } \\
\text { T5 (14-15 years) } \\
\text { T6 ( } 15-16 \text { years) } \\
\text { T7 (17-18 years) } \\
\text { T8 ( } 21 \text { years) } \\
\text { T9 (24 years) } \\
\text { T10 (27 years) } \\
\text { Outcome data collected } \\
\text { at T8, T9, T10 and at T11 } \\
\text { ( } 30 \text { years ) and T12 } \\
\text { ( } 33 \text { years) }\end{array}$ & $\begin{array}{l}\text { Alcohol misuse in the year } \\
\text { prior to any follow-up point. } \\
\text { Lifetime incidence of alcohol } \\
\text { misuse. } \\
\text { Alcohol dependence in the year } \\
\text { prior to any follow-up point. } \\
\text { Alcohol dependence at } \\
\text { multiple follow-up waves } \\
\text { (chronicity of alcohol } \\
\text { dependence). }\end{array}$ & $\begin{array}{l}\text { Gender. Ethnicity. Childhood poverty. Frequency of } \\
\text { substance use during adolescence (including tobacco, } \\
\text { marijuana and other illicit drug use). }\end{array}$ & 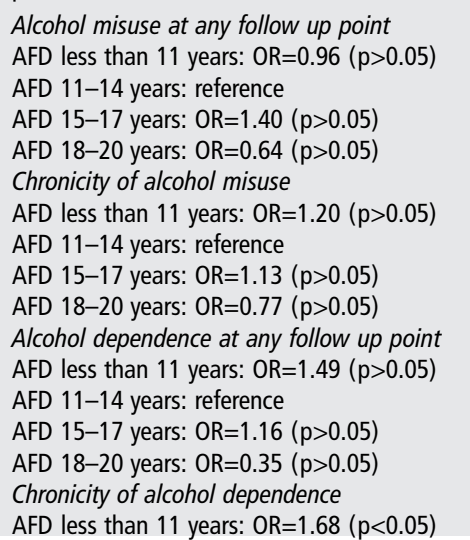 \\
\hline
\end{tabular}




\begin{tabular}{|c|c|c|c|c|c|c|c|}
\hline & & & & & & & $\begin{array}{l}\text { AFD 11-14 years: reference } \\
\text { AFD 15-17 years: } O R=1.04(p>0.05) \\
\text { AFD 18-20 years: }(p>0.05)\end{array}$ \\
\hline $\begin{array}{l}\text { Guttmannova } \\
\text { et al } 2012^{21}\end{array}$ & $\begin{array}{l}\text { Seattle Social } \\
\text { Development } \\
\text { Project. } \\
\text { School-based cohort } \\
\text { (Seattle, USA) }\end{array}$ & 706 & $100 \%$ & $\begin{array}{l}\text { AFD data collected at: } \\
\text { T1 (10-11 years) } \\
\text { T2 (11-12 years) } \\
\text { T3 (12-13 years) } \\
\text { T4 (13-14 years) } \\
\text { T5 (14-15 years) } \\
\text { T6 (15-16 years) } \\
\text { T7 (17-18 years) } \\
\text { T8 ( } 21 \text { years) } \\
\text { T9 ( } 24 \text { years) } \\
\text { Outcome data collected } \\
\text { at T8, T9, T10 (27 years), } \\
\text { T11 ( } 30 \text { years) and T12 } \\
\text { (33 years) }\end{array}$ & $\begin{array}{l}\text { Alcohol dependence at } \\
\text { multiple follow-up waves } \\
\text { (chronicity of alcohol } \\
\text { dependence). }\end{array}$ & $\begin{array}{l}\text { Gender, ethnicity, poverty, parental drinking, family } \\
\text { bonding, family management. } \\
4 \text { multivariable models tested, all including above covariates } \\
\text { and also: } \\
\text { 1. Peer drinking and peer antisocial behaviour. } \\
\text { 2. School achievement. } \\
\text { 3. Delinquency and behavioural problems. } \\
\text { 4. Substance misuse: tobacco, marijuana and heavy } \\
\text { episodic drinking. }\end{array}$ & $\begin{array}{l}\text { Bivariate association between early AFD } \\
(<11 \text { years) and chronicity of alcohol } \\
\text { dependence: regression coefficient } \beta=0.44 \\
\text { ( } p<0.05) \text {. } \\
\text { Magnitude of association remains largely } \\
\text { unaffected in } 4 \text { separate regression models, } \\
\text { aiming to test hypotheses that association is } \\
\text { attributable to other predictive factors. } \\
\text { Model 1: Peer factors } \beta=0.53(p<0.01) \\
\text { Model 2: School factors } \beta=0.46(p<0.05) \\
\text { Model 3: Behavioural factors } \beta=0.45 \\
\text { ( } p<0.05) \\
\text { Model 4: Substance misuse factors } \beta=0.46 \\
(p<0.05)\end{array}$ \\
\hline
\end{tabular}

AFD, age of first drinking. 


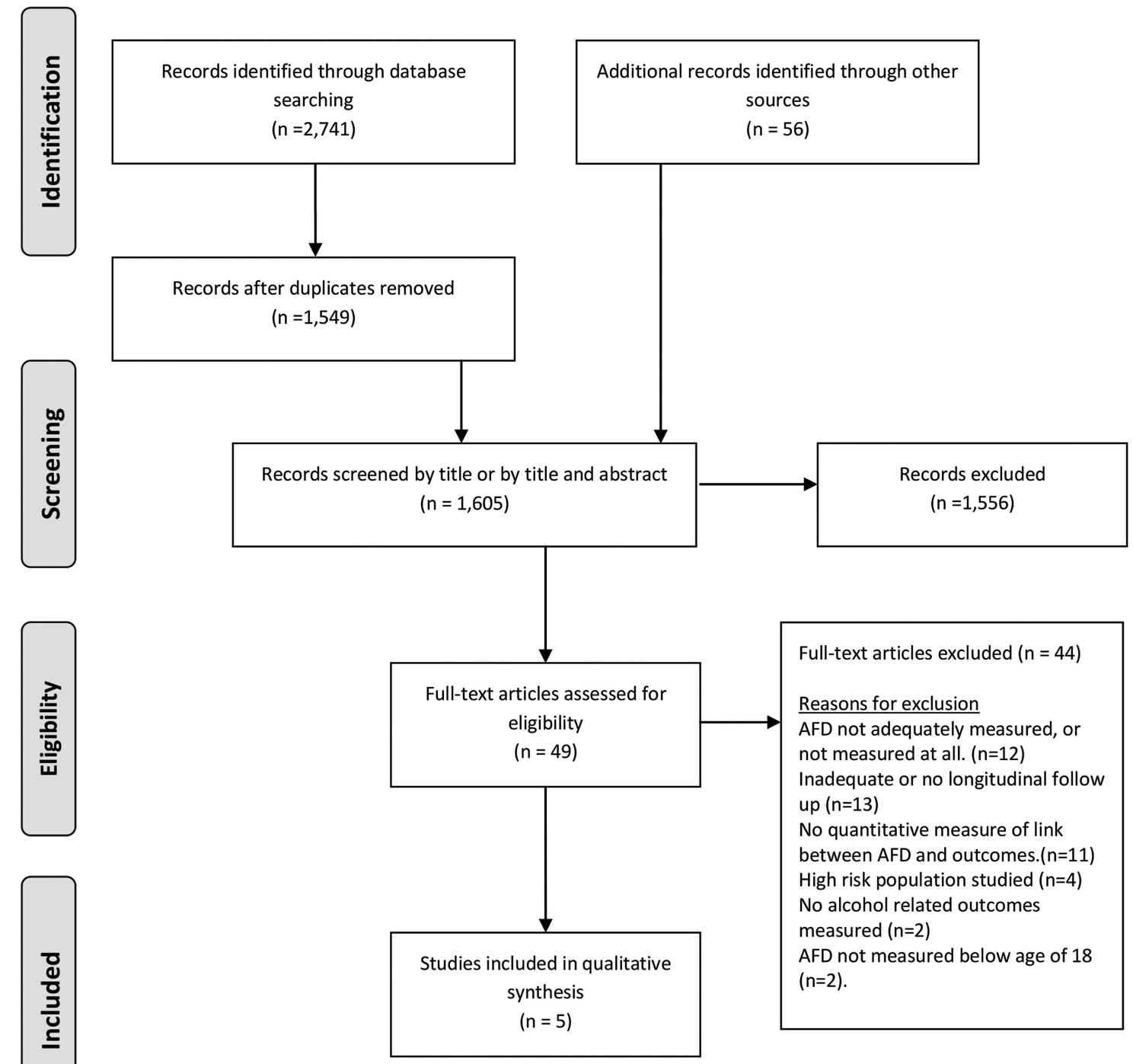

Figure 1 Flow diagram to show process of identifying and screening studies for inclusion. AFD, age of first drinking.

also for other risk factors (regression coefficient: -0.0631 , $\mathrm{p}>0.05)$. The strongest predictor of adult alcohol problems was whether one felt drunk at first episode and this was highly significant in all analyses, including the multivariable model with the most rigorous adjustment for confounders (regression coefficient: $0.3848, \mathrm{p}<0.0001)$.

Guttmannova et $a l^{20}$ investigated possible effects on adult alcohol misuse and dependence (whether any within 12 months prior to interview and for how many follow-up waves) of AFD and the initiation of regular drinking among a sample of 808 people who had initiated drinking prior to the US legal age of 21 years. For analysis purposes AFD was categorised into four age ranges, less than 11 years old, 11-14 years old, 15-17 years old and 18-20 years old. Data on alcohol-related outcomes were collected at 3-yearly intervals from age 21 years to age 33 years. The authors found no association between AFD and alcohol misuse. While AFD was not related to the occurrence of any diagnosis of dependence to age 33 years, it was associated with the number of interviews for which a past year diagnosis was applicable, with AFD before 11 years being at elevated risk compared with ages 11-14 years in a model controlling for demographic and other adolescent substance use variables (OR 1.68, $\mathrm{p}<0.05)$. The authors were particularly interested in evaluating a sensitive period hypothesis, that vulnerability was greater if AFD occurred between ages 11 years and 14 years, and found no evidence to support this. Although AFD itself was not generally associated with adult alcohol problems, the authors found that initiation of regular drinking between 15 years to 17 years of age was consistently associated with alcohol misuse and dependence.

A later report by this group evaluated the finding of an association of AFD with chronicity of dependence in a subset of 706 people in the same cohort in greater detail after splitting the exposure into AFD before age 11 years or not. ${ }^{21}$ This study extension was principally concerned to test three competing hypotheses for the association between AFD and chronicity of dependence using mediation analyses in structural equation regression models. These hypotheses related to: confounding by other risk factors (the marker hypothesis, see later); developmental impairment leading to greater involvement with alcohol; and increased adolescent substance use. None of these hypotheses were supported. ${ }^{21}$

In a study of 1311 people, Rossow and Kuntsche ${ }^{22}$ used a binary measure of whether participants reported alcohol consumption by age 13-14 years as their exposure variable, based 
on questions about the most recent drinking occasion. Participants were followed up once at age 26-27 years to measure adult alcohol consumption patterns. At follow-up, AFD by age 13 years or 14 years was associated with frequent intoxication (OR 1.5: 95\% CI 1.2 to 1.9) and high Alcohol Use Disorders Identification Test (AUDIT) scores (OR 1.6: 95\%CI 1.3 to 2.1) in models adjusting only for gender. When the authors also adjusted for conduct problems in adolescence, these ORs attenuated and were no longer statistically significant (OR for frequent intoxication, 1.2: 95\% CI 0.9 to 1.6, OR for high AUDIT scores, 1.2: 95\% CI 0.9 to 1.6). The authors identify these findings as coherent with findings from studies with other designs which suggest that delaying AFD will not reduce alcohol problems in adulthood. ${ }^{22}$

\section{DISCUSSION}

The most important study finding is the meagre evidence base available, with only a small number of heterogeneous studies providing an insecure basis for making conclusions on the relationship between AFD and adult alcohol problems. There is some evidence of at least small, rather inconsistent, effects of AFD on adult alcohol problems in all studies, however these effects attenuate or disappear with more rigorous control for confounding. The included studies are not without limitations which are important to consider before drawing conclusions.

Attrition does not generally present a significant threat of bias as follow-up rates were in excess of $80 \%$ in all studies. Perhaps of greater relevance were the various forms of selection employed in sample construction, particularly for the smaller studies, which mean that generalisability of findings must be carefully considered. The definition of the exposure, AFD, among included studies is robust, with studies excluded if this was problematic. ${ }^{23} 24$ Similarly outcome measurement is reliable, generally making use of validated measures, and where there are minor deviations from Diagnostic and Statistical Manual of Mental Disorders, for example in timeframes used, these are well justified.

Most studies used a rigorous approach to AFD measurement by collecting data on this variable at multiple points during adolescence, and taking the first report of alcohol use in their analysis. ${ }^{18-21}$ Confounding is most extensively controlled for by Warner and White ${ }^{19}$ with reasonable levels of control also employed by Guttmannova et $a l^{20} 21$ and to a lesser extent by Rossow and Kuntsche. ${ }^{22}$ The possibility of overadjustment should be borne in mind, where for example peer variables may lie on the causal pathway to adult outcomes as well as being implicated in earlier AFD.

As with any systematic review of observational studies, we may have missed studies meeting inclusion criteria if the AFD or outcome data were not prominently reported. We examined all studies included in a related systematic review, ${ }^{16}$ and went to great lengths in identifying further studies through subject experts. If there is significant publication bias and included studies represent a biased sample of all studies that have been undertaken, then overestimation of associations will have occurred. Given the somewhat contested nature of alcohol and drugs issues, this area seems highly vulnerable to publication bias. $^{25} 26$ This possibility seems likely to occur where preliminary explorations of cohort study datasets are deemed to yield no interesting findings. ${ }^{16}$ It is striking that there were no reports drawn from birth cohort studies and we judge that the possibility of publication bias poses a profound threat to the certainty with which any inferences can be made on this subject.

Other limitations of this small literature should also be borne in mind. There are no included studies from low income and middle income countries, or from any country with a Mediterranean culture. The consequences of earlier AFD should be expected to vary cross-culturally, as early socialisation processes may promote or inhibit learning behavioural control, and alcohol harms are also managed in different ways in different cultures.

Study findings are broadly consistent with the results of a prospective case-control study of children of alcoholics, which was not included in the review and found that earlier AFD was unrelated to alcohol dependence when confounding factors were taken into account. ${ }^{27} \mathrm{~A}$ similar pattern of results was seen in two studies based on the very large (more than 40000 participants) National Epidemiologic Survey on Alcohol and Related Conditions (NESARC) cohort, representative of the population of the USA. ${ }^{28} 29$ These were excluded from the present review by virtue of the absence of AFD measurement in adolescence and are thus vulnerable to recall and related biases. Both found small effects of AFD on adult outcomes.

The finding of a weak or absent association between AFD and later alcohol problems, after observed associations are attenuated with rigorous control for confounders, provides some support for a marker hypothesis. ${ }^{8}$ Put simply, those who possess an underlying vulnerability to alcohol problems may also be likely to start drinking early. Further support for the marker hypothesis may be inferred from the lack of strong evidence for the long-term effectiveness of interventions which aim to reduce alcohol related harm by preventing underage drinking. ${ }^{12} 3031$ These reviews suggest that delaying AFD does not impact on long-term problems. The most recent findings by Guttmannova et $a l^{21}$ rejecting a marker hypothesis should, however, be borne in mind.

Among the studies that were included, larger and arguably more important effects on the risk of adult alcohol problems were observed in relation to feeling drunk during the first episode and the initiation of regular drinking than AFD itself. $^{19} 20$ These variables representing more significant involvement in alcohol use, or lying a little further along a putative causal pathway, and showing more noteworthy effects, are important to consider carefully. AFD may represent an important event in the acquisition of this new behaviour, whose effects are much more likely to be felt on proximal rather than distal outcomes. $^{163233}$ The characteristics of the first event, such as were studied by Warner and White, and other early drinking episodes should be fruitful to explore. ${ }^{34}$

Despite the challenges involved in interpreting the detail of study findings, the sparse data available carry implications for policy makers. There is no strong evidence for delaying AFD as a means of preventing future adult alcohol problems. However, because alcohol is an important cause of car crashes, violence and suicide, the leading causes of death among adolescents and young people globally, ${ }^{35}$ there remains a clear rationale for interventions seeking to help young people avoid or better manage alcohol consumption, regardless of whether earlier AFD is a causal component in the aetiology of adult alcohol problems. Decision making in relation to prevention should thus be based on the acute and short-term harms associated with drinking among children and adolescents rather than on uncertain long-term harms.

The most important implication, however, of the findings of this study is the need to develop a very underdeveloped literature in order to support evidence-based prevention practice. Apart from the early study by Pedersen and Skrondal with weak control for confounding, ${ }^{18}$ the existence of effects of AFD on adult drinking and related problems is supported, but not at all strongly in the first study by Guttmannova et al. ${ }^{20}$ The opposite possibility is supported by the second study from that cohort, and those by Rossow and Kuntsche and Warner and 
White. ${ }^{19} 2122$ This rather mixed evidence available from the aforementioned studies, and also the strong likelihood of publication bias indicates the need for caution in making inferences about any such effects. The most sensible conclusions are that we do not yet know whether starting drinking earlier leads to adult alcohol problems and that we need to develop our understanding of drinking behaviour, across the life course and across the globe.

\section{What is already known on this subject}

A proposed relationship between an early onset of drinking and alcohol problems in adulthood has been used as an important rationale to justify efforts to prevent drinking among children and young people. Although a number of observational studies appear to support this relationship, the evidence for such a link has not previously been systematically examined.

\section{What this study adds}

There is a meagre evidence-base of high-quality cohort studies to evaluate the relationship between an earlier onset of drinking and adult alcohol problems. These studies do not provide clear evidence of a causal relationship. Policy makers should concentrate on minimising the acute and short-term harms associated with drinking among children and adolescents rather than on uncertain long-term harms.

Acknowledgements The authors are grateful to David Batty for comments on a draft of this paper.

Contributors WM: conceptualised and designed the study, carried out data collection and analysis, wrote the first draft of the manuscript and approved the final manuscript as submitted. JM conceptualised and designed the study, carried out data collection and analysis, revised the manuscript and approved the final manuscript as submitted.

Funding The work of the second author was supported by a Wellcome Trust Research Career Development Fellowship in Basic Biomedical Science (WT086516MA).

\section{Competing interests None.}

Provenance and peer review Not commissioned; externally peer reviewed.

Open Access This is an Open Access article distributed in accordance with the Creative Commons Attribution Non Commercial (CC BY-NC 3.0) license, which permits others to distribute, remix, adapt, build upon this work non-commercially, and license their derivative works on different terms, provided the original work is properly cited and the use is non-commercial. See: http://creativecommons.org/ licenses/by-nc/3.0/

\section{REFERENCES}

1 U.S. Department of Health and Human Services OotSG. The Surgeon General's Call to Action to Prevent and Reduce Underage Drinking. U.S, 2007.

2 Donaldson L. Guidance on the consumption of alcohol by children and young people. A report by the Chief Medical Officer. Department of Health, 2009.

3 Grant BF, Dawson DA. Age at onset of alcohol use and its association with DSM-IV alcohol abuse and dependence: results from the National Longitudinal Alcohol Epidemiologic Survey. I Subst Abuse 1997;9:103-10.

4 Hingson RW, Heeren T, Winter MR. Age at drinking onset and alcohol dependence: age at onset, duration, and severity. Arch Pediatr Adolesc Med 2006;160:739-46.

5 York JL, Welte J, Hirsch J, et al. Association of age at first drink with current alcohol drinking variables in a national general population sample. Alcohol ClinExp Res 2004;28:1379-87.

6 DeWit DJ, Adlaf EM, Offord DR, et al. Age at first alcohol use: a risk factor for the development of alcohol disorders. Am J Psychiatry 2000;157:745-50.
7 Rossow I. Inferences of associations and implications for prevention: the case of early drinking onset. In: Elster I GO, Hylland A, Moene K. eds. Understanding choice, explaining behaviour: essays in honour of Ole-Jørgen Skog. Oslo, Norway: Oslo Academic Press, 2006:259-72.

8 Prescott CA, Kendler KS. Age at first drink and risk for alcoholism: a noncausal association. Alcohol Clin Exp Res 1999;23:101-7.

9 Buchmann AF, Schmid B, Blomeyer D, et al. Impact of age at first drink on vulnerability to alcohol-related problems: testing the marker hypothesis in a prospective study of young adults. J Psychiatr Res 2009;43:1205-12.

10 Sartor CE, Bucholz KK, Nelson EC, et al. Reporting bias in the association between age at first alcohol use and heavy episodic drinking. Alcohol Clin Exp Res 2011;35:1418-25.

11 OCEBM Levels of Evidence Working Group. The Oxford 2011 Levels of Evidence, 2011.

12 Foxcroft DR, Ireland D, Lister-Sharp DJ, et al. Primary prevention for alcohol misuse in young people. Cochrane Database Syst Rev 2002;(3):CD003024.

13 Moher D, Liberati A, Tetzlaff J, et al. Preferred reporting items for systematic reviews and meta-analyses: the PRISMA statement. BMJ 2009;339:b2535.

14 American Psychiatric Association. Diagnostic and statistical manual of mental disorders (Revised 4th ed.). Washington, DC: American Psychiatric Association, 2000.

15 World Health Organisation. International statistical classification of diseases and related health problems tenth revision (ICD-10). World Health Organization, 4th edn. Geneva, 2010.

16 McCambridge J, McAlaney J, Rowe R. Adult consequences of late adolescent alcohol consumption: a systematic review of cohort studies. PLoS Med 2011;8: e1000413.

17 Sartor CE, Lynskey MT, Heath AC, et al. The role of childhood risk factors in initiation of alcohol use and progression to alcohol dependence. Addiction 2007;102:216-25.

18 Pedersen W, Skrondal A. Alcohol consumption debut: predictors and consequences. J Stud Alcohol 1998:59:32-42.

19 Warner LA, White HR. Longitudinal effects of age at onset and first drinking situations on problem drinking. Subst Use Misuse 2003;38:1983-2016.

20 Guttmannova K, Bailey JA, Hill KG, et al. Sensitive periods for adolescent alcohol use initiation: predicting the lifetime occurrence and chronicity of alcohol problems in adulthood. J Stud Alcohol Drugs 2011;72:221-31.

21 Guttmannova K, Hill KG, Bailey JA, et al. Examining explanatory mechanisms of the effects of early alcohol use on young adult alcohol dependence. I Stud Alcohol Drugs 2012;73:379-90.

22 Rossow I, Kuntsche E. Early onset of drinking and risk of heavy drinking in young adulthood-a 13-year prospective study. Alcohol Clin Exp Res 2013;37(Suppl 1): E297-304.

23 Pitkänen T, Kokko K, Lyyra A-L, et al. A developmental approach to alcohol drinking behaviour in adulthood: a follow-up study from age 8 to age 42. Addiction 2008; 103:48-68

24 Grant BF, Stinson FS, Harford TC. Age at onset of alcohol use and DSM-IV alcohol abuse and dependence: a 12-year follow-up. J Subst Abuse 2001;13:493-504.

25 McCambridge J. A case study of publication bias in an influential series of reviews of drug education. Drug Alcohol Rev 2007;26:463-8.

26 McCambridge J. A response to the commentaries: look away now or face up to the profound problem of publication bias in drug education research. Drug Alcohol Review 2008;27:352-56

27 King KM, Chassin L. A prospective study of the effects of age of initiation of alcohol and drug use on young adult substance dependence. I Stud Alcohol Drugs 2007;68:256-65

28 Hingson RW, Heeren T, Winter MR. Age of alcohol-dependence onset: associations with severity of dependence and seeking treatment. Pediatrics 2006;118:e755-63.

29 Dawson DA, Goldstein RB, Chou SP, et al. Age at first drink and the first incidence of adult-onset DSM-IV alcohol use disorders. Alcohol Clin Exp Res 2008:32:2149-60.

30 Spoth R, Greenberg M, Turrisi R. Preventive interventions addressing underage drinking: state of the evidence and steps toward public health impact. Pediatrics 2008;121(Supplement 4):S311-36.

31 Foxcroft DR, Tsertsvadze A. Universal multi-component prevention programs for alcohol misuse in young people. Cochrane Database Syst Rev 2011;(9):CD009307.

32 Labouvie E, Bates ME, Pandina RJ. Age of first use: its reliability and predictive utility. I Stud Alcohol 1997;58:638-43.

33 McCambridge J, Strang J. Age of first use and ongoing patterns of legal and illegal drug use in a sample of young Londoners. Subst Use Misuse 2005;40:313-19.

34 Warner LA, White HR, Johnson V. Alcohol initiation experiences and family history of alcoholism as predictors of problem-drinking trajectories. I Stud Alcohol Drugs 2007:68:56-65.

35 Gore FM, Bloem PJN, Patton GC, et al. Global burden of disease in young people aged 10-24 years: a systematic analysis. Lancet 2011;377:2093-102. 